\title{
Condition Assessment of Passive MRTB Based on Fuzzy Theory
}

\author{
Jing Dai \\ China Electric Power Research Institute \\ Wuhan, China \\ daijingxxx@163.com
}

\begin{abstract}
As one of the core equipment of high-voltage direct-current (HVDC) transmission system, the health status of passive MRTB would directly threaten the secure and stable operation of power system. Aiming at correctly getting the real-time operating status of passive MRTB , a new condition assessment method base on fuzzy theory is proposed and the corresponding device has been developed in this paper. After sampling the oscillating current, this method calculates arcing time by wavelet theory ,then fuzzy theory is used to judge the operating status of passive MRTB.
\end{abstract}

Keywords-High-voltage direct-current (HVDC) system, passive Metal Return Transfer Breaker (MRTB), Condition Assessment, Fuzzy Theory,

\section{INTRODUCTION}

Being a new transmission style, HVDC transmission system quickly becomes an important means of long distance electric power transmission because of its huge transmitting capacity, long transmitting distance and low wire loss[1,2]. As HVDC system develops, HVDC circuit breakers, is playing a more significant role in securing the safety and stability of HVDC system.

Present researches are focused on the designing of the body of MRTB and conversion of diverse running status[3]. Literature[4] proposed a compact MRTB on the bottom of helical flux compression generators. Literature[5] proposes a method to monitor the status of the commutation path of MRTB . AND YET these researches have made a magnificent contribution in improving the safety and stability of HVDC CBs. However, applying of HVDC CBs is impeded by the discoordination of commutation path ,nominal current path and energy absorption path[6].

This paper, on the background of a $500 \mathrm{kV}$ convert station, proposes an online condition assessing method and devises a corresponding device. This method effectively reduces much work and improves the reliability and economy of HVDC systems.

\section{WORKING PRINCIPLE OF MRTB}

Compare to $\mathrm{AC}$ interrupting, $\mathrm{DC}$ interrupting is characterized by the absence of natural current zero crossing and enormous energy stored in the system inductance[3].As a result, for most MRTBs, a commutation path is used to produce zero-crossings by superimpose the oscillating current to the nominal DC current. And a parallel absorbing path made up of $\mathrm{ZnOs}$ is applied to absorb the energy.
Fig.1 shows the structure of passive MRTB. It comprises three parts: $\mathrm{AC}$ interrupter $\mathrm{CB}$, commutation path made of a capacitor $\mathrm{C}$ (consists of capacitors), an inductor $\mathrm{L}$, a resister $\mathrm{R}$, energy absorbing path consists of $\mathrm{ZnOs.}$

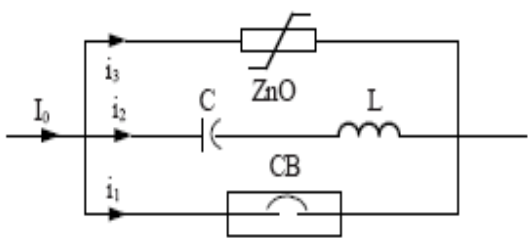

Fig. 1 The structure of MRTB

When MRTB receives break command, CB breaks and meanwhile the commutation path begin to produce a high frequency oscillating current. By superimposing this oscillating current on the DC current, zero crossing appears and $\mathrm{CB}$ can blow out the arc. Then capacitor $\mathrm{C}$ was charged by DC current until $\mathrm{ZnOs}$ act and absorb the energy.

Since MRTB works under sequential control, it should theoretically be reliable. However, breaking faults of MRTB always happens in practice. For the safety and reliability of HVDC system, to assess the condition of MRTB timely is indispensable.

\section{CONDITION Assessment OF PASSIVE MRTB BASED ON FUZZY THEORY}

Conception of fuzzy system is first introduced by Zadeh in 1973. It is by far widely used in the condition assessment of power transformers and AC interrupters[7].

In view of the current situation of MRTB condition assessment, this paper proposes a fuzzy theory based method. This method uses wavelet theory to analyse the waveform of oscillating current to calculate arcing time and then substitute it into subordinating degree function to obtain the health status of MRTB.

\section{A. Arcing time calculating}

Among the many arcing models, the Schwarz model is more widely used and is closer to the practical process of arcing. The fomula is as follow[8]:

$$
\frac{1}{g} \frac{d g}{d t}=\frac{d \ln g}{d t}=\frac{1}{\tau g^{a}}\left(\frac{u i}{P g^{b}}-1\right)
$$

Where $u$ and i represent the voltage and current of the arc respectively, $\tau$ and $\mathrm{P}$ represent the time constant and 
dissipating power, $\mathrm{a}$ and $\mathrm{b}$ are the effecting coefficients of $\mathrm{g}$ tozand $\mathrm{P}$

Based on this formula, this paper builds a MATLAB simulation model of HVDC breakers and performs an dynamic simulation of the breaking process of the MRTB in the $\pm 500 \mathrm{kV}$ Longquan converter station. Parameters of the MRTB in Gezhouba converter station is shown in table 1.

TABLE I MAIN PARAMETERS OF MRTB

\begin{tabular}{|l|l|l|l|}
\hline Number & Item & Unit & Value \\
\hline 1 & Rated current & Adc & 3486 \\
\hline 2 & Rated voltage & KVdc & 50 \\
\hline 3 & Max voltage & KVdc & 137 \\
\hline 4 & Operation voltage of ZnO & KVdc & 120 \\
\hline 5 & $\begin{array}{l}\text { Capacitance of commutation } \\
\text { path }\end{array}$ & $\mu F$ & 30 \\
\hline 6 & $\begin{array}{l}\text { Reactance of } \\
\text { commutation path }\end{array}$ & $\mathrm{uH}$ & 50 \\
\hline
\end{tabular}

The simulation model is as follows:

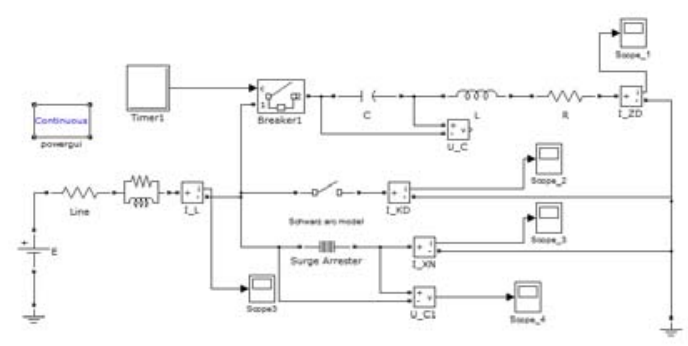

Fig.2 Simulation model of MRTB

As showed in fig.3, under normal condition, when MRTB begin to break, a high frequency oscillating current with a great amplitude emerged. $0.202 \mathrm{~s}$ later, the frequency drops and the current curve becomes smooth, indicating that the arc quenched and DC current transferred to the commutation path. Then the amplitude declined obviously, which is a result of the action of $\mathrm{ZnOs}$.

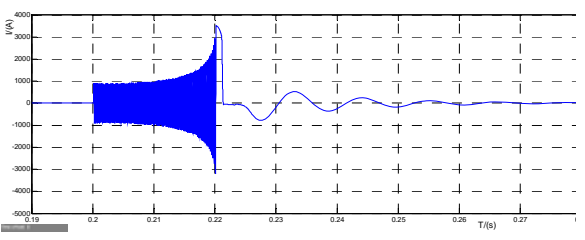

Fig.3 Oscillating current waveform under normal condition

Because of the arc's resistance, the oscillating current waveform is different when there is no arc. Thus by detecting the point at which the damping changes we can determine the starting point and ending point of arcing. Then wavelet tools are used to decompose the waveform to acquire the point of the sudden change of damping. By this method, the starting and quenching point of arc and arcing time can be precisely obtained.

\section{B. Condition assessment}

The arcing time parameters of interrupters mainly include maximum arcing time $\mathrm{Tm}$ and standard arcing time
Tw. If practical arcing time exceeds Tm, interrupter will not be able to extinguish the arc.

When maximum arcing time Tm, standard arcing time Tw and the present practical arcing time is determined, this paper choose dropping semi-trapezoid function as subordinating degree function to form a fuzzy system to assess the status of MRTB.

While a long arcing time shows the unhealthy status of MRTB, a short arcing time indicates the healthy status of MRTB. Assume the healthy index is V, then

$$
V=\left\{\begin{array}{l}
1, \quad T<=T_{w} \\
\frac{T_{m}-T}{T_{m}-T_{w}}, T_{w}<T<=T_{m} \\
0, T>T_{m}
\end{array}\right.
$$

$\mathrm{V}$ is a value between 0 and 1. In practice, MRTB's status can be divided into several ranks. According to long term experience, this paper divides MRTB's status into four ranks and relate $\mathrm{V}$ with the four ranks as shown in table 2

TABLE II MRTB HEALTH STATUS V

\begin{tabular}{|l|l|l|}
\hline V's value & status & Description \\
\hline $0-0.2$ & faulty & $\begin{array}{l}\text { Faults have occurred, should } \\
\text { be overhauled instantly }\end{array}$ \\
\hline $0.2-0.4$ & warning & A fault is near, should be overhauled timely \\
\hline $0.4-0.8$ & common & $\begin{array}{l}\text { In a common state, should } \\
\text { be overhauled on schedule }\end{array}$ \\
\hline $0.8-1$ & good & In a good state, no need to overhaul \\
\hline
\end{tabular}

After calculating $\mathrm{V}$, we can make sure whether the MRTB needs to be overhauled and make plans about when to overhaul it so as to secure the safety and stability of HVDC system.

\section{REALIZATION OF CONDITION AsSESSMENT DEVICE.}

According to the method mentioned above, this paper devised a corresponding condition assessment system. Considering the field constraints, this system connect background assessing center with the collecting device of each MRTB by a combination of Internet and GPRS technology. The center can assess the health status of each MRTB so as to overhaul them timely.

\section{A. Collecting Device}

A Hall sensor is choosed in the device. It can not only measure the current accurately, but also has no contact with MRTB. To deal with strong interference ,PAC, or BECKHOFF CX1020,which has an excellent functioning ability and a low consumption, is employed in this device. To ensure a high sampling frequency, a corresponding data collecting module EL3702 is applied.

Because the collecting device is fixed on a high voltage insulating platform, an external energy source is not accessible. A combination of a battery of large capacity and 
solar energy boards is used to guarantee that the device can work continuously and steadily.

The physical map of collecting device can be seen in Fig.4. Fig. 4 shows the picture of the component in the box.

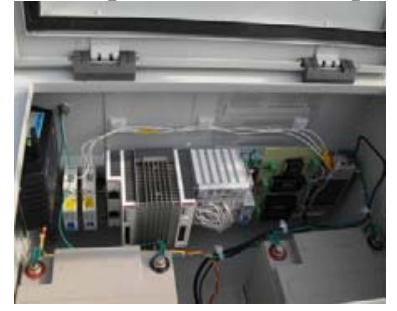

Fig.4 stereogram of collecting device

\section{B. Background Assessment Center}

Background assessment center is the core part of the MRTB condition assessment system. It is responsible for analyzing the collected current, calculating arcing time by wavelet theory and V by fuzzy theory. After assessment, results are sent to decision center to make repair schedule. The structure is shown in Fig.5.

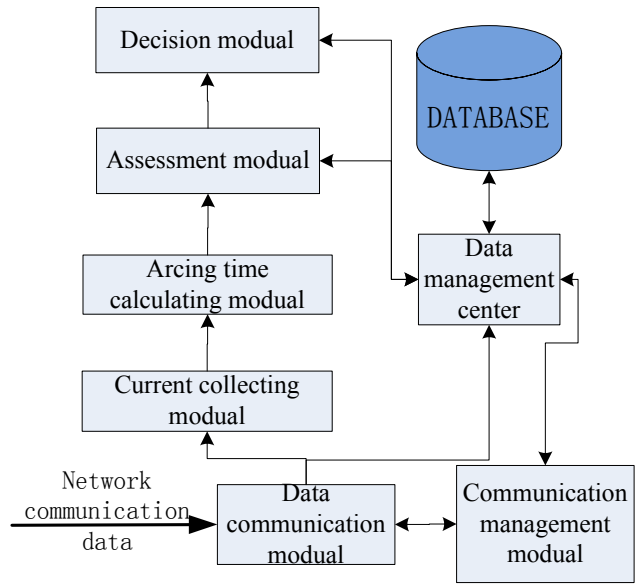

Fig.5 Structure of background assessment center

\section{SUMMARY}

This paper illustrates the working principle of MRTB and proposed a condition assessment method of MRTB and then devises a corresponding device. Compared to conventional offline measuring, this method contains the following merits:

No need to change the original connecting wires, and able to working online for a long term independently.

Wavelet theory can accurately calculate arcing time, and fuzzy theory can correctly obtain the health status of MRTB.

Greatly reduces much work and improves the reliability and economy of HVDC systems.

\section{REFERENCES}

[1]. Adapa, R., High-Wire Act: HVdc Technology: The State of the Art. Power and Energy Magazine, IEEE, 2012. 10(6): p. 18-29.

[2].Sian Green. HVDC Systems Gotland: the HVDC Pioneer[J]. Power Engineering International,2004, 12(7): 28- 29.

[3].Christian M. F. HVDC Circuit Breakers: A Review Identifying Future Research Needs[J]. IEEE Trans. on Power Delivery, 2011, 26(2), 998-1007.

[4]Jouya Jadidian. A Compact Design for High Voltage Direct Current Circuit Breaker. IEEE Transaction on Plasma Science, 2009, 37(6), 1084-1091.

[5].Jun Wang,Tao Ning,Zhihua Li,Wei chen," Realization of Monitoring systems of DC Breaker Based on GPRS Technology",The 3rd International Conference on Comoutational Intelligence and Industrial Application,December 2010.

[6].H. Nakao, Y. Nakagoshi, M. Hatano, et al. D.C. urrent Interruption in HVDC SF6 Gas MRTB by Means of Self-Excited Oscillation Superimposition[J]. IEEE Trans. On Power Delivery, 2001, 16(4): 687-693.

[7].Zhong, W., et al. State Assessment System of Power Transformer Equipments Based on Data Mining and Fuzzy Theory. in Intelligent Computation Technology and Automation (ICICTA), 2010 International Conference on. 2010. Changsha.

[8]Schavemaker P H. Arc model blockset[DB].Power Systems Laboratory, Delft University of Technology, the Nether lands(eps.et.tudelft.nl), 